\title{
ESTUDO DE CASO DE ESTRUTURA DE AÇO EM SITUAÇÃO DE INCÊNDIO: EMPREGO DE CURVAS PADRÃO E PARAMÉTRICAS ATRAVÉS DE MÉTODOS SIMPLIFICADOS E AVANÇADOS
}

\author{
Aleff Marques de Amorim ${ }^{1}$ \\ Pedro Augusto Oliveira de Carvalho ${ }^{2}$ \\ Thiago Dias de Araújo e Silva ${ }^{3}$ \\ Adriano dos Guimarães ${ }^{4}$
}

\section{RESUMO}

Estudos relacionados à Segurança Contra Incêndio constituem assunto de elevada importância para a sociedade. Este fenômeno tem grande relevância em edifícios de estruturas de aço, dada sua alta condutividade térmica e a redução das propriedades mecânicas com 0 aumento da temperatura. Entretanto, as normas pertinentes em vigor apresentam algumas limitações, principalmente quando se trata de metodologias avançadas de cálculo e incêndio natural, as quais geralmente suscitam dimensionamentos muito conservadores da proteção contra incêndio. Diantedo exposto, é proposta por este trabalho a verificação de uma estrutura de aço em situação de incêndio, de maneira a buscar um dimensionamento de proteção contra incêndio mais realista. Realizou-se uma comparação entre métodos simplificados de cálculo propostos pelas normas ABNT NBR 14323:2013 e EN 1993-1-2 (2010) e análises avançadas utilizando MEF (Método dos Elementos Finitos), baseandose nas curvas de Incêndio Padrão ISO-834 e de Incêndio Natural. Por fim, fezse o dimensionamento utilizando tabelas padronizadas por fabricantes, seguido da comparação de custos obtidos pelos métodos propostos. Concluiu-se que ao utilizar metodologia de cálculo avançada (MEF) com a curva de incêndio natural, na maioria dos casos, obteve-se um dimensionamento da proteção passiva mais econômico.

Palavras-chave: Incêndio. Aço. Estruturas de aço. Proteção contra incêndio.

\footnotetext{
${ }^{1}$ Graduado em Engenharia Civil pelo Instituto Federal de Educação, Ciência e Tecnologia do Tocantins (IFTO). Email: eng.aleffmarques@gmail.com

${ }^{2}$ Graduado em Engenharia Civil pelo Instituto Federal de Educação, Ciência e Tecnologia do Tocantins (IFTO).

${ }^{3}$ Doutor em Engenharia Civil pela Universidade de Aveiro, Portugal (UA). Professor Efetivo do IFTO.

${ }^{4}$ Mestre em Engenharia Civil pela Universidade do Rio de Janeiro. Professor Efetivo do IFTO.
} 


\title{
CASE STUDY OF STEEL STRUCTURE IN FIRE SITUATION: USE OF STANDARD AND PARAMETRIC CURVES BY SIMPLIFIED AND ADVANCED METHODS
}

\begin{abstract}
Studies related to Fire Safety are a matter of great importance for society. This phenomenon has great relevance in steel structure buildings, given its high thermal conductivity and the thermal properties reduction as the temperature grows. However, relevant regulations use to bring overlapping approaches, mainly when talking about advanced methodologies and natural fire, which often give rise to very conservative fire protection design. In view of the above, it is proposed by this work the verification of a steel structure in a fire situation, in order to seek a more realistic fire protection design. A comparison was made between simplified calculation methods proposed by ABNT NBR 14323:2013 and EN 1993-1-2 (2010) and advanced analyzes using FEM (Finite Element Method), based on Standard Fire ISO-834 and Natural Fire curves. Finally, a sizing was done using tables standardized by manufacturers, followed by the cost comparison obtained by the proposed methods. It was concluded that, by using advanced methodology (FEM) with Natural Fire curves, in most of the cases, a more economic design of the fire protection design was obtained.
\end{abstract}

Keywords: Fire. Steel. Steel Structures. Fire Protection. 


\section{INTRODUÇÃO}

Eventos de incêndio de ampla relevância suscitaram a elaboração de estudos mais aprofundados sobre SCI (Segurança Contra Incêndio). "Ao longo do século $X X$, muitos dos avanços na proteção contra incêndio aconteceram como reação à ocorrência de grandes incêndios" (CAMPOS, 2012, p.9).

Para edificações construídas em estruturas de aço, do ponto de vista estrutural, o risco de incêndio é intensificado por inúmeros fatores. Apesar de apresentar diversas propriedades superiores a outros sistemas estruturais, como leveza, agilidade e precisão na construção, maior facilidade em vencer vãos, sua elevada condutividade térmica é uma desvantagem a ser ponderada (MESQUITA, 2013).

Esta propriedade térmica carrega consigo a necessidade de uma maior atenção no que tange a possíveis situações de incêndio, visto que altas temperaturas afetam drasticamente suas características de resistência mecânica. Como afirmam Bellei et al (2008, p. 199), muitos dos tipos de aços comerciais "têm sua resistência reduzida em $50 \%$ a partir da temperatura média de $550^{\circ} \mathrm{C}$ ".

A Norma Brasileira ABNT NBR 14323:2013 "estabelece os requisitos para o projeto das estruturas de aço [...] em situação de incêndio [...] conforme os requisitos de resistência ao fogo, prescritos pela ABNT NBR 14432" (ASSOCIAÇÃO BRASILEIRA DE NORMAS TÉCNICAS, 2000, p.1). A partir desta norma são definidas as metodologias aceitas nacionalmente para dimensionamento desse tipo de estrutura. Além desta, outras normas são amplamente difundidas e utilizadas internacionalmente, como as Normas Europeias EN 1991-1-2:2010 e EN 1993-1-2:2010, que tratam respectivamente das ações em estruturas expostas ao fogo e da verificação da resistência ao fogo em estruturas de aço.

As análises segundo metodologias prescritivas preveem a verificação de elementos individuais da estrutura, baseadas em uma curva de incêndio 
normalizado. Este tipo de metodologia não leva em conta a existência de elementos de proteção passiva ou ativa. Ainda, de acordo com Vila Real (2003), limita-se a temperatura do aço à temperatura de colapso do elemento exposto ao incêndio padrão, sem considerar as circunstâncias e particularidades em que a estrutura é sujeita ao incêndio, como qual o tipo do incêndio ou das consequências de carregamento.

Alternativamente a esta metodologia, é possível realizar a análise de estruturas de aço em situação de incêndio de acordo com uma perspectiva que considere o desempenho dos elementos estruturais.Este tipo de análise é baseado no comportamento físico do material, onde são consideradas diversas variáveis. É levada em conta ainda a avaliação das medidas passivas e ativas de segurança, culminando, geralmente, em estratégias mais econômicas. A ABNT NBR 14323:2013 define os métodos avançados de cálculo como aqueles que proporcionam uma análise realística da estrutura e do cenário do incêndio (ASSOCIAÇÃO BRASILEIRA DE NORMAS TÉCNICAS, 2013).

A evolução destes modelos vem acompanhada de um notável progresso acadêmico no desenvolvimento de métodos analíticos voltados à $\mathrm{SCl}$ nos últimos anos, e ao aparecimento de programas de cálculo baseados no Método de Elementos Finitos (MEF), para simular o comportamento das estruturas em situação de incêndio.

Entretanto, ainda existem pontos a serem estudados nesta área do conhecimento, dada a indução ao dimensionamento simplificado por parte das prescrições normativas, acompanhado da facilidade alvitrada por dimensionamentos baseados em tabelas, considerando uma temperatura crítica constante para todos os elementos da estrutura.Estes tendem ao superdimensionamento da proteção passiva, com resultados geralmente negativos em relação aos custos de implantação, tornando-o por vezes menos competitivo. Há, portanto, uma busca por parte da indústria de tornar mais competitivos os edifícios em aço. Bellei (2008, p. 26) demonstra que cerca de 8 a $15 \%$ dos custos em estruturas de aço são provenientes da proteção passiva, 
os quais poderiam serem reduzidos caso houvesse uma análise mais aprofundada do desempenho e das características do local.

Diante do exposto, este trabalho propõe-se a demonstrar que, em análises de estruturas de aço sob a ação do fogo, estudos baseados no desempenho do material tem mais propensão à eficácia do que modelos prescritivos e empíricos. Será, portanto, realizada uma comparação entre estes métodos através do dimensionamento de um edifício industrial em estruturas de aço, utilizando para isso as curvas de incêndio padrão e natural, a fim de evidenciar a viabilidade econômica das abordagens avaliadas.

\section{REVISÃO BIBLIOGRÁFICA}

O presente tópico busca expor os pontos mais relevantes relacionados à análise térmica e estrutural de pórticos de aço em situação de incêndio, descrevendo conceitos básicos a serem empregados durante a pesquisa. Serão abordadas as curvas de incêndio a serem utilizadas, bem como os procedimentos empregues para a verificação da resistência mecânica das estruturas de aço em situação de incêndio através de métodos de cálculo simplificados e avançados.

\section{Análise Térmica}

A análise térmica é o estudo do desenvolvimento e da distribuição de temperatura nas peças estruturais (ASSOCIAÇÃO BRASILEIRA DE NORMAS TÉCNICAS, 2013). A resistência ao fogo dos elementos estruturais é estudada através da reação ao calor dos materiais. As características mecânicas do material aquecido são reduzidas e esforços solicitantes de origem térmica são desenvolvidos, o que provoca uma sobrecarga na estrutura, cuja simulação da temperatura é realizada por modelos matemáticos, formulados de maneira a descrever a variação de temperatura do compartimento em função do tempo (COSTA, 2006). 
A Curva de Incêndio-Padrão a ser empregada nesta pesquisa é a proposta pela norma ISO 834 (INTERNATIONAL ORGANIZATION FOR STANDARDIZATION, 1990). Esta possui somente um ramo ascendente, iniciando sua trajetória após o flashover. Junior e Molina (2012) mencionam este tipo de curva de incêndio como útil para a padronização de ensaios, tornando possível a comparação dos resultados para um mesmo material. Entretanto, Reis (2011) lembra o fato de que queelas não levam em conta as dimensões do compartimento, além de desconsiderarem características inerentes ao local, como cargas de incêndio e condições de ventilação. Assim posto, as curvas de incêndio-padrão, como a ISO 834, se mostram incapazes de simular o real comportamento do elemento estrutural analisado em situação de incêndio.

Já as curvas de incêndio natural são definidas na norma ABNT NBR 14432 (2000, p.3) como a "variação de temperatura que simula o incêndio real, função da geometria, ventilação, características térmicas dos elementos de vedação e da carga de incêndio específica". Segundo este tipo de análise, existem diferentes estudos para o cálculo da temperatura em compartimentos de incêndio, os quais podem ser classificados como simplificados ou avançados.

As curvas de incêndio natural admitem, racionalmente, que os gases que envolvem o fogo não têm sua temperatura sempre crescente com o tempo. Antes, a temperatura dos gases respeita as curvas temperatura-tempo naturais, baseadas em ensaios que buscam simular a situação real de um compartimento em chamas (SILVA, 2001). Estas curvas carregam em seus modelos matemáticos as considerações de cargas de incêndio no ambiente, compartimentação, taxas de aberturas e até mesmo medidas de proteção ativa, de forma a tornar a análise mais próxima da realidade. 


\section{Análise Mecânica}

É fundamental para os estudos do impacto da elevação de temperatura nas estruturas de aço, entender como estas se comportam ao longo do tempo de exposição ao fogo. Segundo Martins (2000), para que a estrutura suporte as cargas adicionais por um tempo mínimo estabelecido, é necessário verificar tanto a resistência dos componentes estruturais, como o comportamento das ligações e a estabilidade da estrutura sob condições de elevadas temperaturas.

As normas EN 1993-1-2:2010 e ABNT NBR 14323:2013 apresentam diferentes maneiras de verificação das estruturas em situação de incêndio. Destas, estabelecem as etapas para o cálculo da resistência ao fogo dos elementos estruturais em aço para elementos isolados, as quais são realizadas por meio da aplicação de equações simplificadas dispostas nestas normas (COUTO, 2011). Silva (2016) elenca as principais hipóteses para o cálculo do valor da resistência utilizando as metodologias simplificadas: i) a temperatura é considerada uniforme na seção transversal; ii) o valor de cálculo da resistência à temperatura normal é modificado para considerar as propriedades mecânicas do aço a elevadas temperaturas; iii) considera-se que o valor das ações não se altera durante $o$ incêndio e consequentemente os efeitos dessas ações se mantêm constantes ao longo do incêndio.

De outro modo, um modelo avançado de cálculo deve ser capaz de considerar as ações térmicas relevantes e a variação das propriedades térmicas dos materiais com a temperatura. Deve-se levar em conta ainda os efeitos das tensões e deformações induzidas termicamente decorrentes do aumento de temperatura e das temperaturas diferenciais. (ASSOCIAÇÃO BRASILEIRA DE NORMAS TÉCNICAS, 2013). Optou-se para esta pesquisa a utilização do software SAFIR (FRANSSEN, 2005). Este foi desenvolvido na Universidade de Liége, na Bélgica, o qual é capaz de acomodar vários elementos para simulações, procedimentos de cálculo e vários modelos de materiais para incorporar no comportamento (SILVA, 2016). 
Por ser baseado em MEF, o SAFIR é capaz de discretizar a seção dos elementos em fibras, associando as propriedades do material analisado. Quanto ao colapso, o critério é definido como sendo o instante em que a sua matriz de rigidez deixa de ser positiva, não sendo mais possível estabelecer 0 equilíbrio da estrutura (LOPES et al, 2005). Este não ocorre necessariamente no instante da ruína de um elemento para estruturas hiperestáticas, visto que o software considera o rearranjo das tensões.

Há ainda uma consideração de dimensionamento de proteção passiva para estruturas de aço que leva em conta o fator de massividade dos perfis metálicos e uma temperatura crítica fixa. Estes são baseados em ensaios padronizados realizados à luz das normativas vigentes, como a ABNT NBR 5628:2001, que trata dos métodos de determinação da resistência ao fogo para componentes construtivos estruturais. As variações em espessura de revestimento se dão devido às características do material de revestimento, a carga crítica e quanto ao fator de massividade do elemento estrutural. $O$ fator de massividade é definido pela razão entre o perímetro exposto ao fogo e a área da seção transversal do elemento estrutural. A importância deste fator para o estudo da transferência de calor se dá visto que seções mais robustas, as quais tem baixo fator de massividade, apresenta menor velocidade de aquecimento do que seções mais esbeltas (PANNONI, 2015).

Caso se apresente necessário o uso de material de revestimento para proteção passiva, utilizam-se cartas de cobertura, as quais relacionam, portanto, o fator de massividade da seção do elemento com o TRRF, informando a espessura do material de proteção térmica (CARVALHO, 2018). Estas são geralmente publicadas pelos fabricantes de proteção antitérmica, e consideram uma temperatura crítica fixa.

\section{METODOLOGIA}

O estudo foi realizado utilizando como modelo estrutural um edifício industrial localizado na cidade de Palmas - TO. Tal edificação é destinada à 
Revista Científica do Corpo de Bombeiros Militar de Pernambuco

Artigo Publicado no Vol.05 N.13 - Edição Jul a Dez 2019 - ISSN 2359-4829

Versão on-line disponível em: http://www.revistaflammae.com

fabricação de óculos, composta por pavimento térreo, dois pavimentos superiores e laje técnica, com área de $1710,00 \mathrm{~m}^{2}$ por pavimento, e Área Total de $5182,00 \mathrm{~m}^{2}$. Contando com 17,20 metros de altura, dos quais $9,2 \mathrm{~m}$ até 0 piso do último pavimento, sua estrutura possui 11 (onze) pórticos principais, espaçados 5,7m entre si, além de duas escadas de acesso (Figura 1).

Figura 1- Modelo 3D estrutural da edificação, planta baixa do $1^{\circ}$ piso e cortes esquemáticos dos pórticos
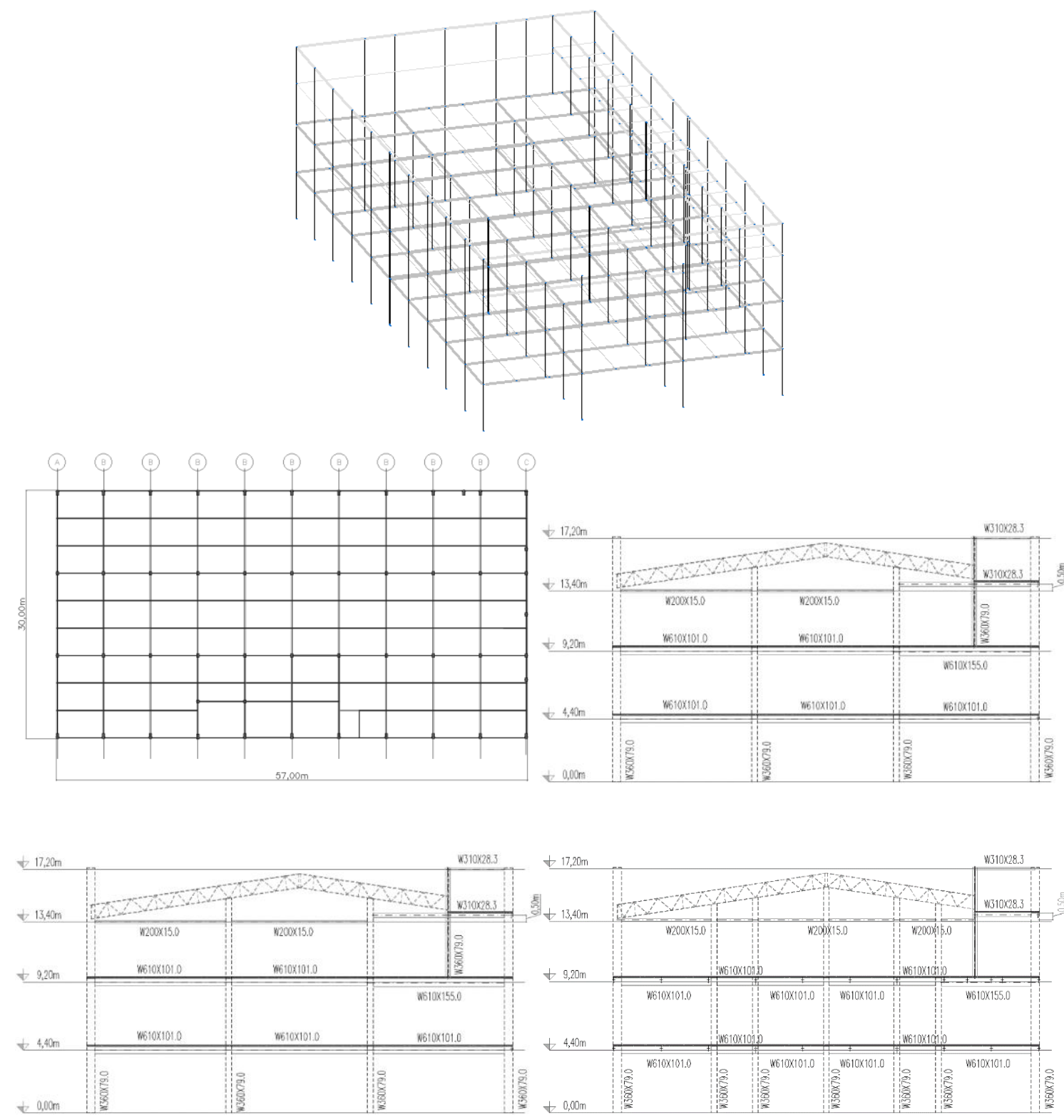
Foram utilizadosdois métodos de verificação das estruturas de aço em situação de incêndio, a saber, um simplificado e um avançado. Inicialmente fezse necessária a definição do TRRF por métodos simplificados, conforme as prescrições normativas, baseando-se na NBR 14432:2000 (ASSOCIAÇÃO BRASILEIRA DE NORMAS TÉCNICAS, 2000). Assim, foi estabelecido o TRRF de 60 minutos para esta estrutura.

Foi desconsiderada a análise de incêndio na laje técnica dado que a mesma contempla dois reservatórios superiores. Quanto ao 20 pavimento, a probabilidade de um incêndio de grandes proporções é baixa, dada sua grande área e as medidas de proteção ativa na edificação, além da isenção de TRRF para coberturas sem função de piso, conforme item 10.1 da NBR 14432 (ASSOCIAÇÃO BRASILEIRA DE NORMAS TÉCNICAS, 2000). Portanto, para este pavimento será analisado incêndio localizado em um dos pilares, o qual é uma variação das curvas de incêndio paramétricas dispostas na EN 1993-12:2010. A norma supracitada também isenta, em seu Anexo A, a necessidade de TRRF maior que 60 minutos para as vigas não pertencentes ao sistema responsável pela estabilidade estrutura da edificação.

\section{Análise segundo a ISO 834}

$\mathrm{Na}$ metodologia simplificada, foi utilizado o software Elefir-EN (VILA REAL e FRANSSEN, 2011). O dimensionamento em situação de incêndio foi realizado de acordo com as formulações da norma EN 1993-1-2:2010, considerando a temperatura uniforme em toda a seção. Conforme Silva (2015), há grande similaridade nos resultados obtidos se comparados com a norma ABNT NBR 14323:2013. As análises são realizadas por barra individualmente, através da inserção dos parâmetros relativos à seção transversal e esforços solicitantes do elemento, seguidos pela definição de camadas expostas ao fogo e de camada de proteção passiva. Em caso de aplicação da camada de proteção, definem-se as características do material de proteção, seguindo, por 
fim, para a determinação da curva de incêndio a ser utilizada. Com estas informações, o programa retorna os dados de temperatura no compartimento, temperatura crítica do perfil e tempo para atingir esta temperatura.

Em seguida foi realizada a mesma verificação utilizando métodos avançados de cálculo, por meio do programa SAFIR (FRANSSEN, 2005). Assim como Silva (2016), para este cálculo foi considerada uma seção transversal discretizada em 108 elementos finitos, a fim de considerar a diferença de temperatura ao longo da seção. Os resultados são visualizados através do módulo Diamond (Figura 2), o qual cumpre função de interface para visualização da deformada dos pórticos. Por realizar uma análise interativa, seu critério de parada se dá no instante de ruptura do primeiro elemento. Dadas as análises, torna-se possível definir quais elementos proteger prioritariamente. Repete-se então a análise com o elemento protegido e identifica-se a necessidade de proteção do próximo, até que se atinja o tempo mínimo requerido.

Figura 2 - Interface do Diamond

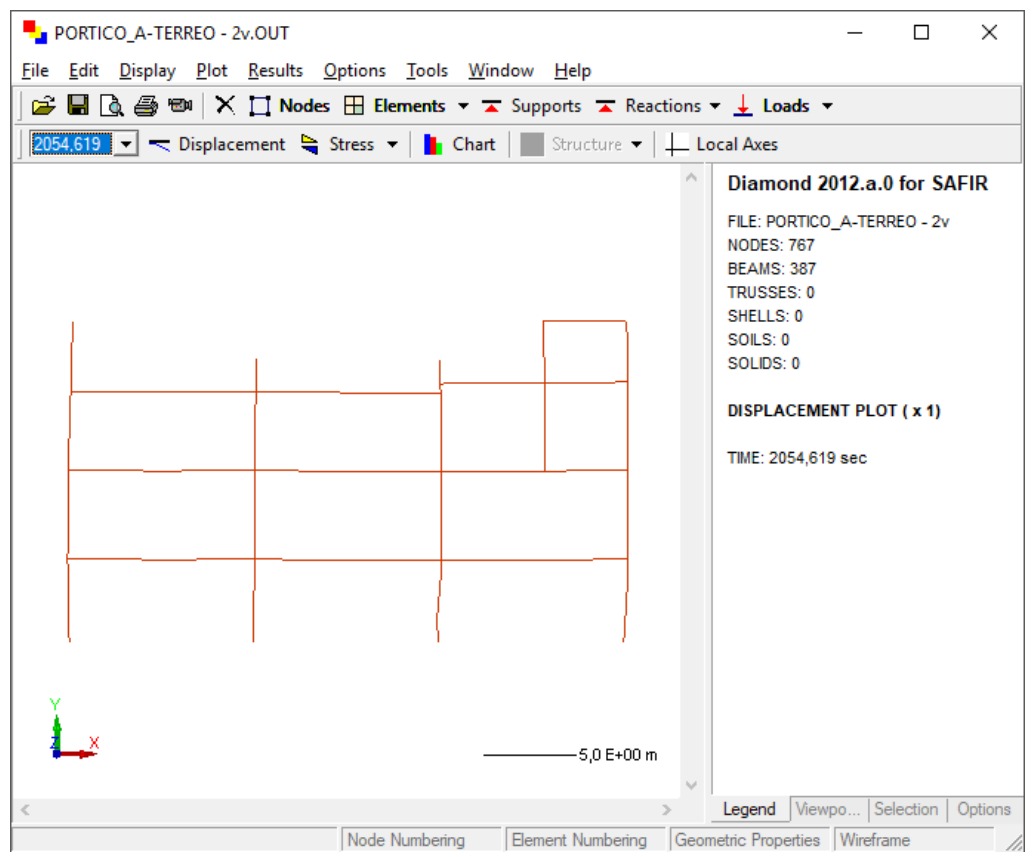




\section{Análise segundo curvas paramétricas}

Dadas as limitações impostas pelo método de análise utilizando curvas paramétricas, leva-se em consideração a compartimentaçãoda edificação de maneira a atender aos requisitos da EN 1993-1-2:2010. Desta forma, os pavimentos analisados foram compartimentados em quatro regiões (Figura 3), definindo o pé direito como 4 metros.

Figura 3 - Compartimentação dos ambientes para análise de incêndio parametrizado

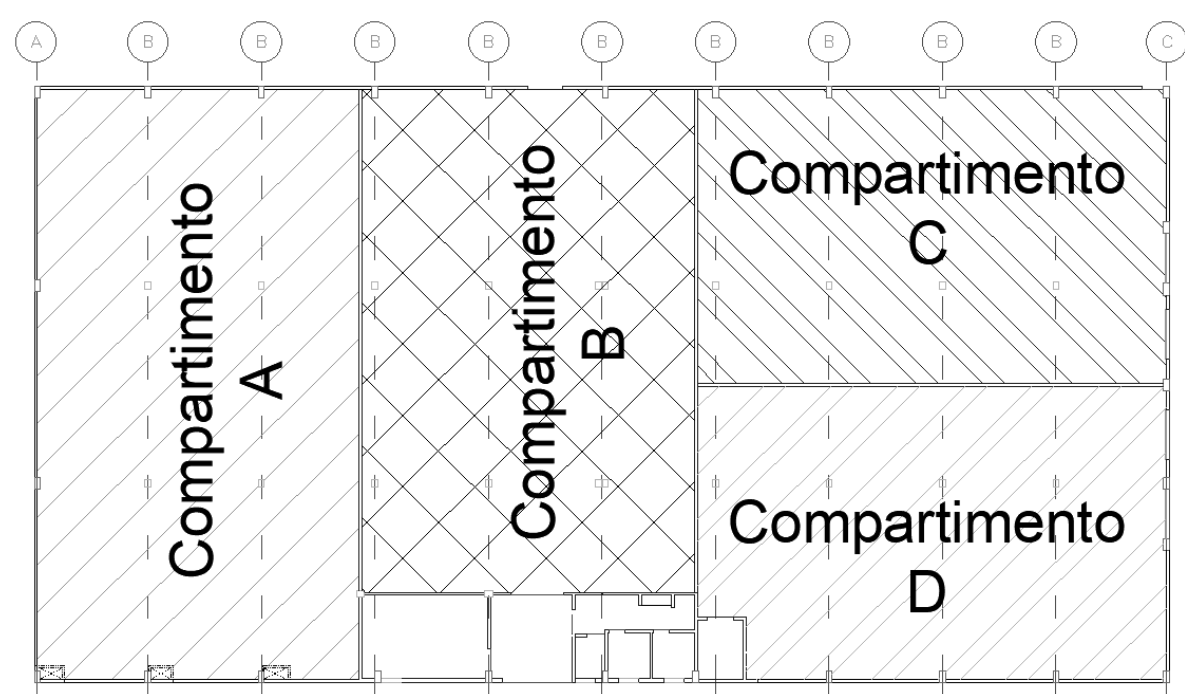

Foram considerados na envoltória o fechamento em alvenaria com revestimento argamassado, sendo o piso em concreto leve e o forro em gesso, cujas características estão listadas na Tabela 1, cujos parâmetros foram retirados do software Elefir-EN. As áreas dos compartimentos e suas respectivas áreas de abertura estão dispostos na Tabela 2.

Tabela 1 - Propriedades da envoltória

\begin{tabular}{c|c|c|c|c}
\hline & $\begin{array}{c}\text { espessura } \\
(\mathrm{cm})\end{array}$ & $\begin{array}{c}\text { massa } \\
\text { unitária } \\
\left(\mathrm{kg} / \mathrm{m}^{3}\right)\end{array}$ & $\begin{array}{c}\text { condutividade } \\
(\mathrm{W} / \mathrm{mK})\end{array}$ & $\begin{array}{c}\text { calor } \\
\text { específico } \\
(\mathrm{J} / \mathrm{kgK})\end{array}$ \\
\hline Paredes & 15 & 1680 & 0.79 & 872 \\
\hline Piso & 10 & 1600 & 0.8 & 840 \\
\hline Forro & 1.5 & 900 & 0.25 & 1000 \\
\hline
\end{tabular}

Fonte: Baseado em VILA REAL, 2011. 
Revista Científica do Corpo de Bombeiros Militar de Pernambuco

Artigo Publicado no Vol.05 N.13 - Edição Jul a Dez 2019 - ISSN 2359-4829

Versão on-line disponível em: http://www.revistaflammae.com

Tabela 2 - Áreas dos compartimentos

\begin{tabular}{c|c|c|c}
\hline Compartimento & Pvto. & Área do compartimento $\left(\mathrm{m}^{2}\right)$ & Área de aberturas $\left(\mathrm{m}^{2}\right)$ \\
\hline A & - & 429.26 & 140.25 \\
\hline B & - & 440.00 & 43.94 \\
\hline \multirow{2}{*}{ C } & Térreo & 346.01 & 59.2 \\
\cline { 2 - 4 } & 10 Pvto. & 346.01 & 51.16 \\
\hline \multirow{2}{*}{ D } & Térreo & 346.01 & 61.80 \\
\cline { 2 - 4 } & 10 Pvto. & 346.01 & 61.60 \\
\hline
\end{tabular}

A carga de incêndio específica foi definida segundo a Tabela C.1 da ABNT NBR 14432" (ASSOCIAÇÃO BRASILEIRA DE NORMAS TÉCNICAS, 2000, p.1) sendo estipulados $1.000 \mathrm{MJ} / \mathrm{m}^{2}$ referente a ambientes com artigos de plástico em geral, material predominante no edifício em questão, o qual enquadra o edifício na classificação $\mathrm{I}-1$ da norma supracitada. Os fatores relacionados ao risco de ativação de incêndio e às medidas de proteção ativa foram definidos de acordo com os elementos existentes na edificação estudada. Assim, considerou-se para a edificação a existência de reserva técnica de incêndio, brigada de incêndio com transmissão de alarme, escada para saída de emergência e sistema de exaustão de fumaça, além da existência de equipamentos de combate a incêndio e de rotas de fuga.

Em seguida foi realizada a mesma verificação utilizando métodos avançados de cálculo por meio do SAFIR, de maneira análoga ao executado para a análise utilizando a curva ISO 834.

\section{Dimensionamento empírico e análise de custo}

Por fim, foi dimensionada a proteção passiva da estrutura através dos métodos empíricos, utilizando-se de cartas de cobertura. O material a ser empregado como revestimento foi a argamassa projetada, em função do custo e da fácil localização de mão-de-obra. Para determinação das camadas, utilizou-se a massividade dos perfis e comparou-se com os valores da carta de cobertura disponibilizada por Placo (2018). 
Dimensionados todos os elementos de revestimento contra fogo através dos métodos propostos, foi realizada uma análise do custo para a implementação. Para tanto, foram utilizados bancos de dados de custos do mercado da construção.

\section{RESULTADOS E DISCUSSÕES}

Os resultados aqui dispostos serão categorizados pórtico a pórtico, onde serão comparados e discutidos os efeitos das análises dos diferentes métodos empregados.

\section{Pórtico A}

\section{Curva ISO-834}

Para determinação das temperaturas nas seções transversais do Pórtico A segundo a curva ISO-834, considerou-se que os elementos estavam expostos ao incêndio em três faces. Através da metodologia simplificada, as temperaturas críticas observadas variaram de $790,1^{\circ} \mathrm{C}$ para o perfil W360X79 utilizado no pilar 01 do pavimento térreo, à $981,5^{\circ} \mathrm{C}$ para o mesmo perfil, utilizado no pilar 01 no $1^{\circ}$ pavimento. Quanto ao TRRF definido, observou-se que o Pórtico A não alcançou o requisito mínimo de segurança (tempo mínimo equivalente a 60 minutos) em nenhum de seus pavimentos analisados, indo a colapso no tempo de 32,05 minutos nas vigas V1.Verificou-se, portanto, que há a necessidade de proteção da estrutura no pórtico, exceto no pilar 01 no $1^{\text {o }}$ pavimento. A espessura mínima de $10 \mathrm{~mm}$ foi adotada para os revestimentos empregados, em detrimento do processo executivo.

Segundo a verificação utilizando a curva ISO 834 a partir do método avançado, observou-se que o Pórtico $A$ não alcançou o requisito mínimo de segurança em nenhum de seus pavimentos analisados, indo a colapso no tempo de 34,23 minutos em incêndio no térreo, 45,47 minutos em incêndio no primeiro pavimento e 33,20 minutos para incêndio nos pavimentos 
simultaneamente. Estes tempos referem-se ao momento em que, durante a análise do pórtico, o primeiro elemento entrou em colapso. A definição dos elementos a serem protegidos pelo método avançado se deu de maneira sequencial, onde se realizava a proteção do primeiro elemento colapsado e se calculava novamente a estrutura, partindo para a proteção do segundo elementoaté que o pórtico não atingisse colapso.Observa-se a redução na necessidade de proteção nos pilares da extremidade para o método avançado (Figura 4).

Figura 4 - Necessidade de proteção passiva nos elementos do Pórtico A, análise ISO 834 simplificada (esquerda) e avançada (direita)

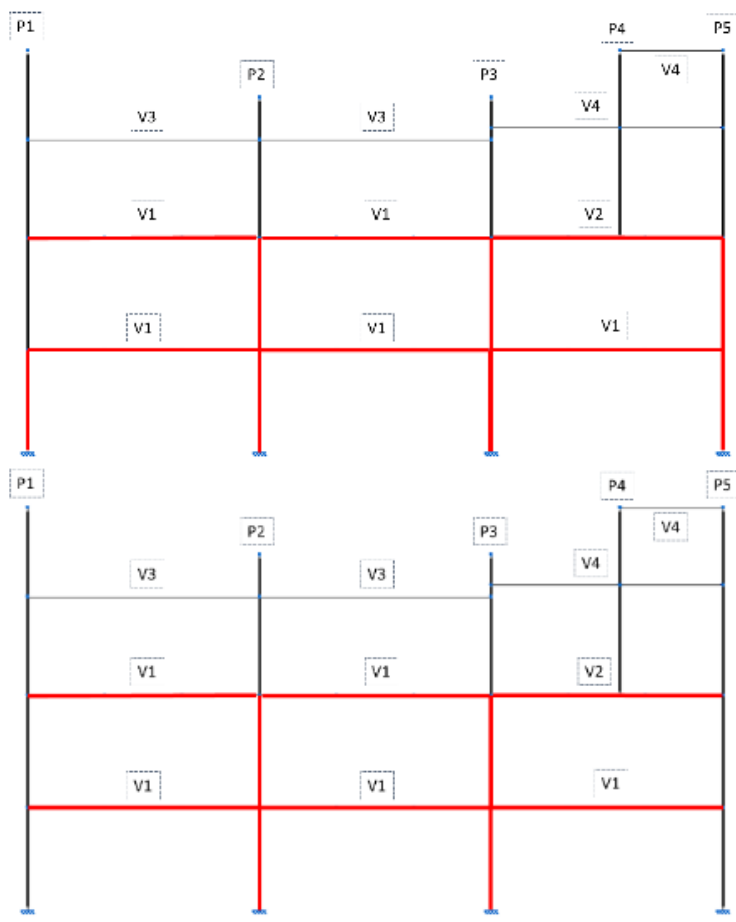

Argamassa projetada $10 \mathrm{~mm}$

\section{Curva Paramétrica}

Quanto à verificação utilizando curvas paramétricas, considerou-se o compartimento $\mathrm{A}$ em ambos pavimentos. As temperaturas críticas variaram de $780.6^{\circ} \mathrm{C}$ para o Pilar 03 no térreo a $981.5^{\circ} \mathrm{C}$ para o Pilar 01 no $1^{\circ}$ pavimento. Já as temperaturas máximas estão entre $1000.94^{\circ} \mathrm{C}$ para a Viga 01 (ver Figura 5) 
até $983.59^{\circ} \mathrm{C}$ para todos os pilares. Verificou-se a necessidade de proteção da estrutura em todos os elementos do pórtico, para que seja assegurada a estabilidade.

Segundo a verificação da situação de incêndio utilizando as curvas paramétricas a partir do método avançado, o Pórtico $\mathrm{A}$ alcançou o requisito mínimo de segurança sem necessidade de revestimento no primeiro pavimento, indo a colapso no tempo de 20,72 minutos em incêndio no térreo e 20,53 minutos para incêndio em ambos os pavimentos simultaneamente.

\section{Figura 5 - Curvas de incêndio para o método simplificado - Viga 01 do Pórtico A}

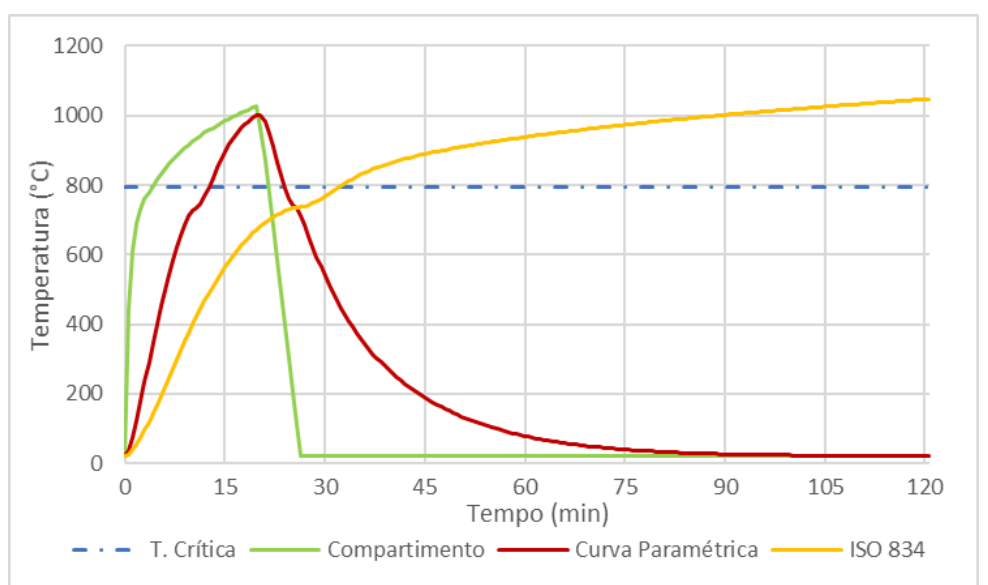

Tem-se na Figura 5 a comparação entre as curvas de temperaturatempo para a viga 01 no pórtico em questão. Observa-se a intensidade e velocidade do flashover para a curva paramétrica, a qual atinge temperaturas elevadas em um curto espaço de tempo. Este processo acontece de maneira aproximada em todos os casos analisados. Entretanto, há uma redução drástica na necessidade de proteção dos elementos para o método avançado neste caso (Figura 6). 
Figura 6 - Necessidade de proteção passiva nos elementos do Pórtico A, análise com curvas paramétricas simplificada (esquerda) e avançada (direita)

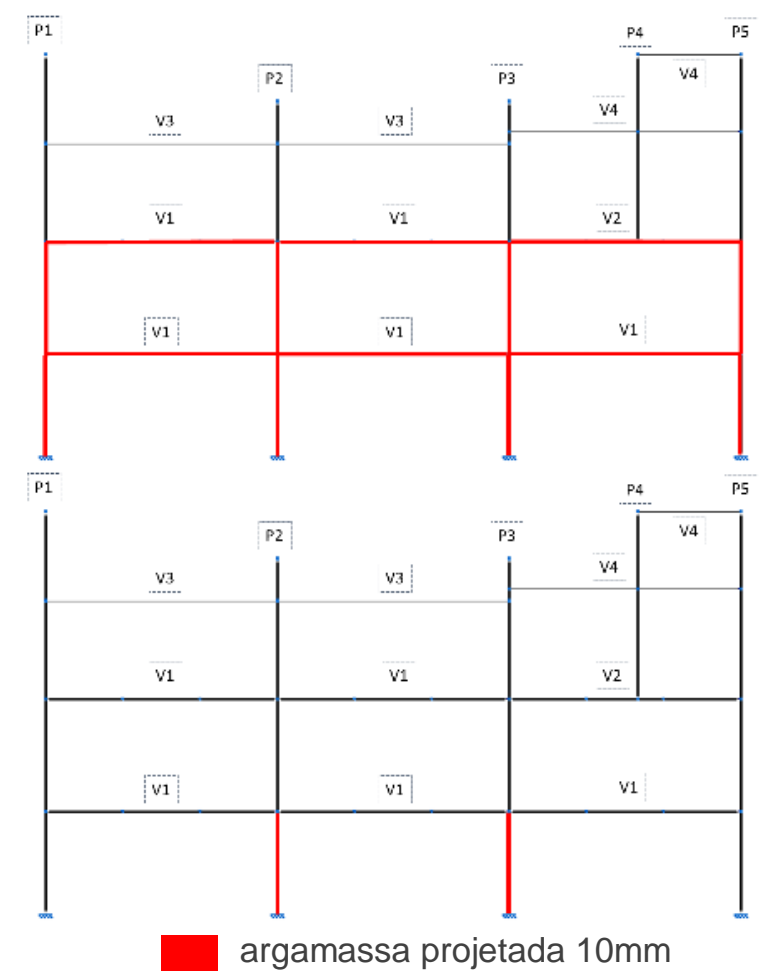

\section{Pórtico B}

O pórtico em questão repete sua geometria ao longo da edificação, estando submetido às mesmas cargas, entretanto compreende compartimentos diferentes em si. Desta forma, são realizadas três análises segundo curvas paramétricas distintas, de acordo com o compartimento em que o pórtico se encontra.

\section{Curva ISO 834}

Para determinação das temperaturas nas seções transversais do pórtico B segundo a curva ISO-834, considerou-se que as vigas e os pilares de extremidade estavam expostos ao incêndio em três faces, e os pilares de centro expostos em quatro faces. Lançando mão da metodologia simplificada, 
as temperaturas críticas observadas variaram de $762,6^{\circ} \mathrm{C}$ para o perfil W610X155 utilizado na viga 02 , à $930,9^{\circ} \mathrm{C}$ para o perfil W360X79, utilizado no pilar 01 no 1 ำ pavimento. Desta forma, o Pórtico B não alcançou o requisito mínimo de segurança em nenhuma das análises, indo a colapso no tempo de 30,68 minutos no pilar 03 no térreo.

Segundo a verificação utilizando a curva ISO 834 a partir do método avançado, o Pórtico B não alcançou o requisito mínimo de segurança em nenhum de seus pavimentos analisados, indo a colapso no tempo de 26,12 minutos em incêndio no térreo, 29,27 minutos em incêndio no primeiro pavimento e 26,40 minutos considerando incêndio em ambos os pavimentos simultaneamente.

Assim, observa-se o acréscimo na necessidade de proteção nas vigas para o método avançado, a qual pode se dar pela consideração da sobreposição de efeitos possibilitada pelo MEF, dada a solicitação de esforços nestes elementos (Figura).

Figura 7 - Necessidade de proteção passiva nos elementos do Pórtico B, análise ISO 834 simplificada (esquerda) e avançada (direita)

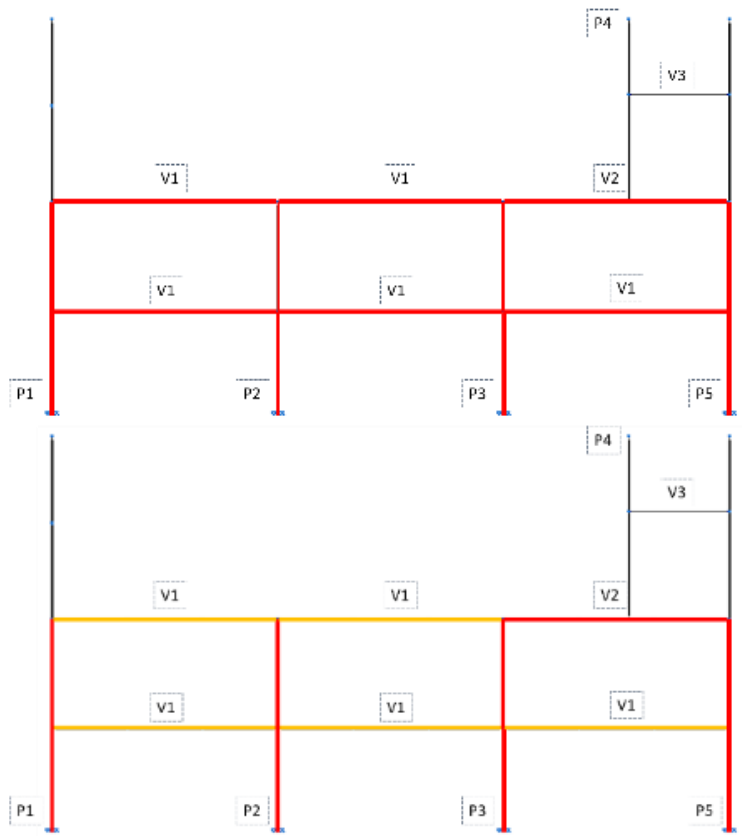




\section{Curvas Paramétricas no Compartimento A}

Quanto à verificação utilizando curvas paramétricas para os pórticos contidos no compartimento $A$, as temperaturas críticas variaram de $762,6^{\circ} \mathrm{C}$ para a viga 02 até $930,9^{\circ} \mathrm{C}$ para o pilar 01 no $1^{\circ}$ pavimento. Já as temperaturas máximas estão entre $1000,94^{\circ} \mathrm{C}$ para a viga 01 até $983.59^{\circ} \mathrm{C}$ para os pilares de extremidade. Verificou-se portantoa necessidade de proteção da estrutura em todos os elementos do pórtico.

Segundo a verificação da situação de incêndio utilizando o método avançado, o Pórtico $B$ não alcançou o requisito mínimo de segurança para nenhum dos casos, indo a colapso no tempo de 14,65 minutos em incêndio no térreo, 12,32 minutos para incêndio no $1^{\circ}$ pavimento e 12,32 minutos para incêndio em ambos os pavimentos simultaneamente.

Tem-se na Figura 8 a comparação entre a necessidade de revestimento contra incêndio de acordo com as abordagens simplificada e avançada. Observa-se a redução na necessidade de proteção nos pilares da extremidade para o método avançado, a qual pode se justificar pela sobreposição de efeitos possibilitada pelo MEF. Esta, se comparada aos resultados obtidos pela análise segundo a ISO 834, também apresenta economia. 
Figura 8 - Necessidade de proteção passiva nos elementos do Pórtico B (Compart. A), análise com curvas paramétricas simplificada (esquerda) e avançada (direita)

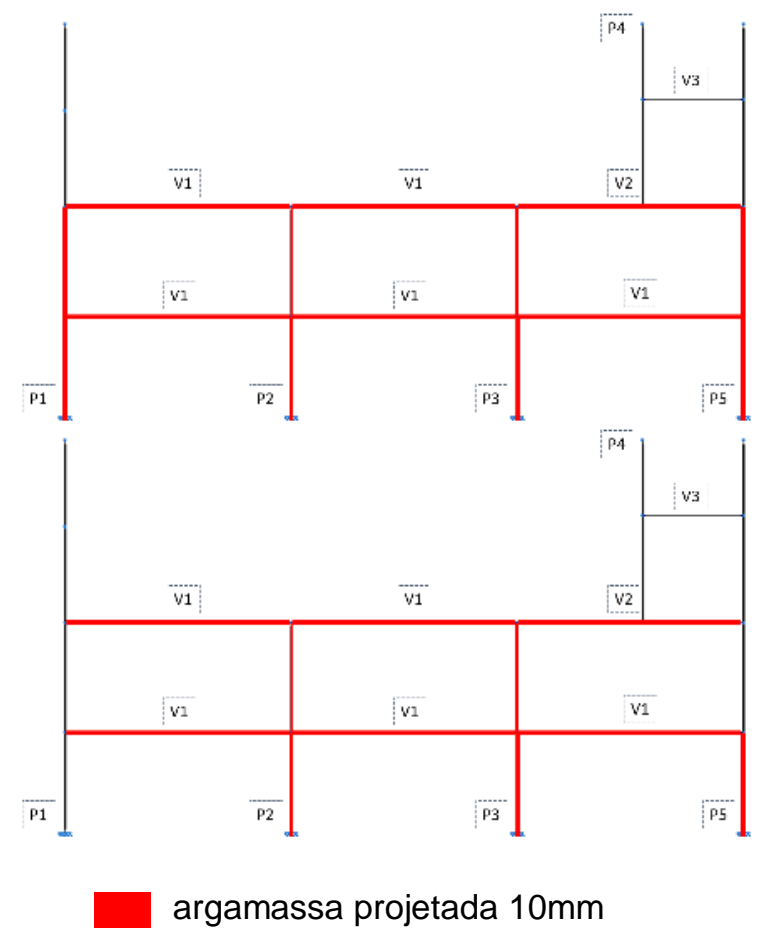

\section{Curvas Paramétricas no Compartimento B}

Quanto à verificação para os pórticos contidos no compartimento $\mathrm{B}$, as temperaturas críticas variaram de $762,6^{\circ} \mathrm{C}$ para a viga 02 até $930,9^{\circ} \mathrm{C}$ para $\mathrm{o}$ pilar 01 no $1^{\circ}$ pavimento. Já as temperaturas máximas estão entre $1073,32^{\circ} \mathrm{C}$ para a viga 02 até $1075,55^{\circ} \mathrm{C}$ para a viga 01 e os pilares centrais. Verificou-se assim a necessidade de proteção da estrutura em todos os elementos do pórtico.

Segundo a verificação utilizando o método avançado para este compartimento, O Pórtico $B$ também não alcança o requisito mínimo de segurança, indo a colapso no tempo de 17,23 minutos em incêndio no térreo, 14,27 minutos para incêndio no 1\% pavimento e 14,60 minutos para incêndio em ambos os pavimentos simultaneamente. 
Conforme representado na Figura 9, enquanto que o método simplificado resultou em revestimentos contra incêndio de $15 \mathrm{~mm}$ nas vigas e pilares centrais, houve redução da necessidade de proteção dos pilares para o método avançado, porém com acréscimo na espessura do revestimento nas vigas 01 .

Figura 9 - Necessidade de proteção passiva nos elementos do Pórtico B (Compart. B), análise com curvas paramétricas simplificada (esquerda) e avançada (direita)

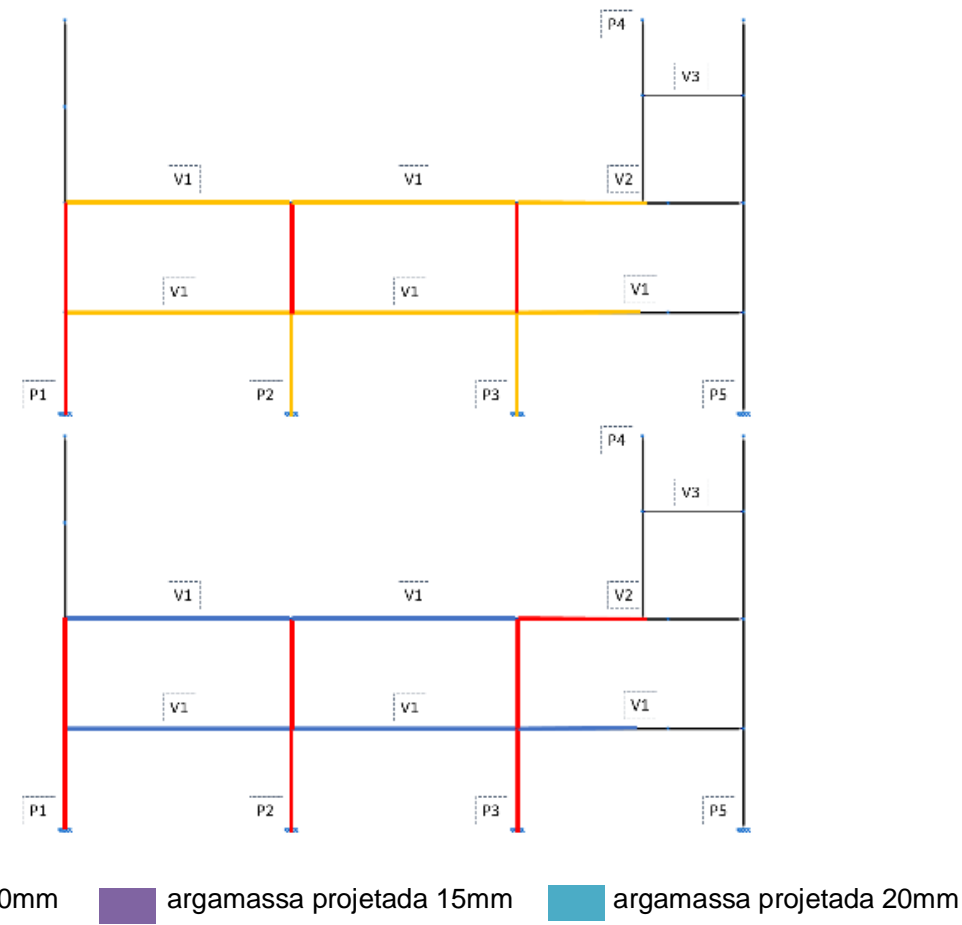

\section{Curvas Paramétricas nos Compartimentos C e D}

Os pórticos intermediários da região posterior da edificação abrangem os compartimentos C e D simultaneamente. Assim, esta análise leva em conta as simulações de situação de incêndio para cada compartimento nos pavimentos. Segundo o método simplificado, verificou-se a necessidade de proteção da estrutura em todos os elementos do pórtico para que seja assegurada a estabilidade. Segundo esta análise, o pórtico entraria em colapso aos 8,60 minutos no pilar 03 do térreo. 
De acordo com a verificação da situação de incêndio empregando o método avançado, o Pórtico $B$ também não alcançou o requisito mínimo de segurança em nenhum dos casos. No compartimento $C$, este vai a colapso no tempo de 10,08 minutos em incêndio no térreo e 11,05 minutos para incêndio no $1^{\circ}$ pavimento. Já para o compartimento $D$, este se colapsa aos 11,58 minutos no térreo e aos 13,10 minutos no $1^{\circ}$ pavimento. Por fim, considerando incêndio em todos os compartimentos, o tempo de colapso seria de 10,10 minutos.

Dada a comparação entre a necessidade de revestimento contra incêndio de acordo com as abordagens simplificada e avançada presentes na Figura 10, observa-se o aumento na necessidade de proteção das vigas para o método avançado, em especial no compartimento $C$ superior.

Figura 10 - Necessidade de proteção passiva nos elementos do Pórtico B (Compart. C e D), análise com curvas paramétricas simplificada (esquerda) e avançada (direita)
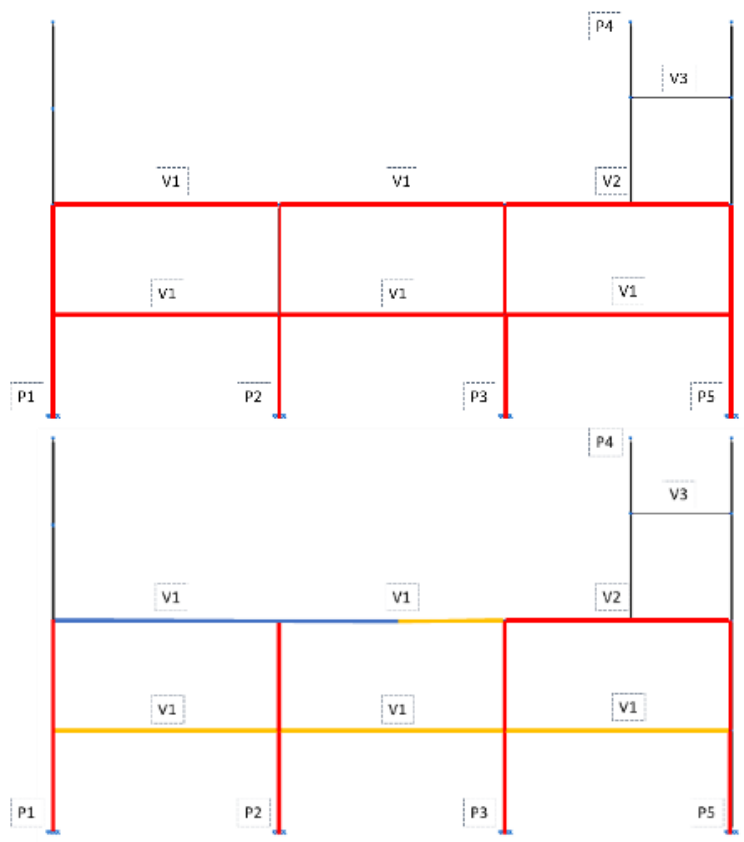


\section{Pórtico C}

Considerou-se para o pórtico em questão a exposição ao fogo de todos os elementos em três faces. O pilar 04, localizado na intermediação dos dois compartimentos, foi analisado exposto nos dois compartimentos para o método das curvas paramétricas, sendo considerada sua situação mais crítica entre as duas.

\section{Curva ISO 834}

Para determinação das temperaturas nas seções transversais do pórtico C segundo a curva ISO-834, e lançando mão da metodologia simplificada, as temperaturas críticas observadas variaram de $836,7^{\circ} \mathrm{C}$ para o perfil W360X79 utilizado no pilar 05 no térreo, à $1126,7^{\circ} \mathrm{C}$ para o perfil W610X105, utilizado nas vigas 02. Quanto ao TRRF definido, observou-se que o Pórtico $C$ não alcançou o requisito mínimo de segurança em nenhum de seus pavimentos analisados, indo a colapso no tempo de 38,57 minutos no pilar 05 no térreo. Verificou-se, portanto, a necessidade de proteção da estrutura no pórtico para todos os elementos.

Segundo a verificação da situação de incêndio utilizando a curva ISO 834 a partir do método avançado, o Pórtico $\mathrm{C}$ alcançou o requisito mínimo de segurança no $1^{\circ}$ pavimento, entretanto este vai a colapso no tempo de 43,02 minutos em caso de incêndio no térreo, ou ainda de 43,40 minutos em caso de incêndio em ambos os pavimentos simultaneamente.

A baixa necessidade de proteção, principalmente nos elementos do $1^{\circ}$ pavimento, se justifica pela baixa solicitação aos elementos em questão. Conforme exposto na Figura 11, nenhum dos pilares do $1^{\circ}$ pavimento necessita de proteção para este caso, reduzindo ainda mais sua necessidade levando em conta o rearranjo dos esforços possibilitado pela metodologia avançada. 
Figura 11 - Necessidade de proteção passiva nos elementos do Pórtico C, análise ISO 834 simplificada (esquerda) e avançada (direita)
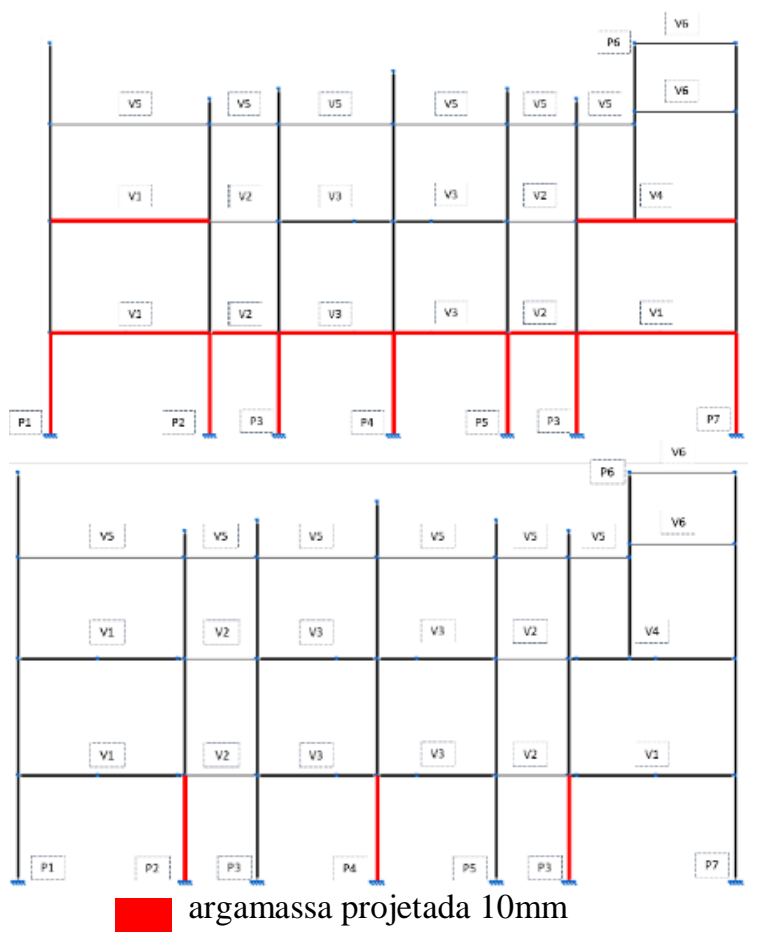

\section{Curvas Paramétricas}

O pórtico em questão abrange os compartimentos C e D. Portanto, esta análise se dá levando em consideração a influência dos compartimentos em que se encontra o pórtico. Segundo o método simplificado, verificou-se a necessidade de proteção da estrutura em todos os elementos do pórtico. Conforme esta análise, o pórtico entraria em colapso aos 9,90 minutos na viga 01 localizado no térreo.

De acordo com a verificação da situação de incêndio empregando o método avançado, o Pórtico $C$ também não alcançou o requisito mínimo de segurança em nenhum dos casos. No compartimento $C$, este vai a colapso no tempo de 19,00 minutos em incêndio no térreo e 22,57 minutos para incêndio no $1^{\circ}$ pavimento. Já para o compartimento $D$, este se colapsa aos 18,43 minutos no térreo e aos 20,65 minutos no $1^{\circ}$ pavimento. Por fim, considerando 
incêndio em todos os compartimentos, o tempo de colapso seria de 16,93 minutos.

Utilizando o método avançado de cálculo através das curvas paramétricas, foi possível alcançar uma redução da necessidade de revestimento contra incêndio em quatro pilares, conforme representado na Figura 12. Entretanto, esta quantidade ainda é maior do que o apresentado na curva ISO 834, em detrimento das características do incêndio de combustão imediata.

Figura 12 - Necessidade de proteção passiva nos elementos do Pórtico B (Compart. C e D), análise com curvas paramétricas simplificada (esquerda) e avançada (direita)
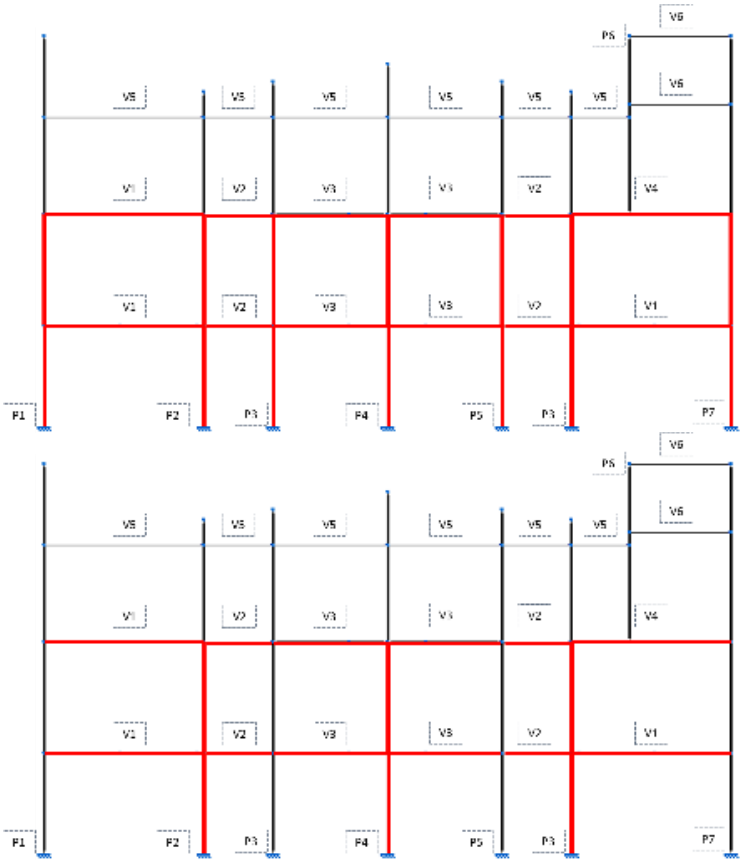

argamassa projetada $10 \mathrm{~mm}$

\section{Incêndio Localizado}

Foram utilizadas neste estudo, para fins de análise utilizando as curvas paramétricas no $2^{-}$pavimento, as recomendações de Incêndio Localizado descrito no Eurocódigo EN-1991-1-2:2010. Para tanto, foi analisado o Pilar 01 do Pórtico B. 
Para tal, empregou-se o modelo de Heskestad (CEN, 2010a; REIS, 2011). A área total de aberturas verticais considerada foi de $269,48 \mathrm{~m}^{2}$ com altura média das aberturas de 2,20m, área máxima de incêndio equivalente a $4 \mathrm{~m}^{2}$, distância entre a origem do incêndio e o teto de $4,20 \mathrm{~m}$, densidade da carga de incêndio de $1.000,00 \mathrm{MJ} / \mathrm{m}^{2}$ e altura ao longo do eixo da chama de $2,0 \mathrm{~m}$.

Os resultados da análise para o pilar em questão podem ser vistos na Figura 13, cujo gráfico foi obtido através do software Elefir-EN (VILA REAL e FRANSSEN, 2011). A temperatura máxima no perfil foi de $427,4^{\circ} \mathrm{C}$ atingida aos 22,98 minutos sendo, portanto, insuficiente para atingir sua temperatura crítica de $1163,8^{\circ} \mathrm{C}$. A temperatura máxima no compartimento é de $492,3^{\circ} \mathrm{C}$ entre $5 \mathrm{e}$ 21 minutos, a partir do qual começa a diminuir até a extinção. Analisando o mesmo perfil segundo a curva ISO 834 , este atingiria sua temperatura crítica após 260,32 minutos de incêndio, portanto não necessita de proteção.

\section{Figura 13 - Curva de Incêndio Localizado para o Pilar 01 no $2^{\circ}$ pavimento}

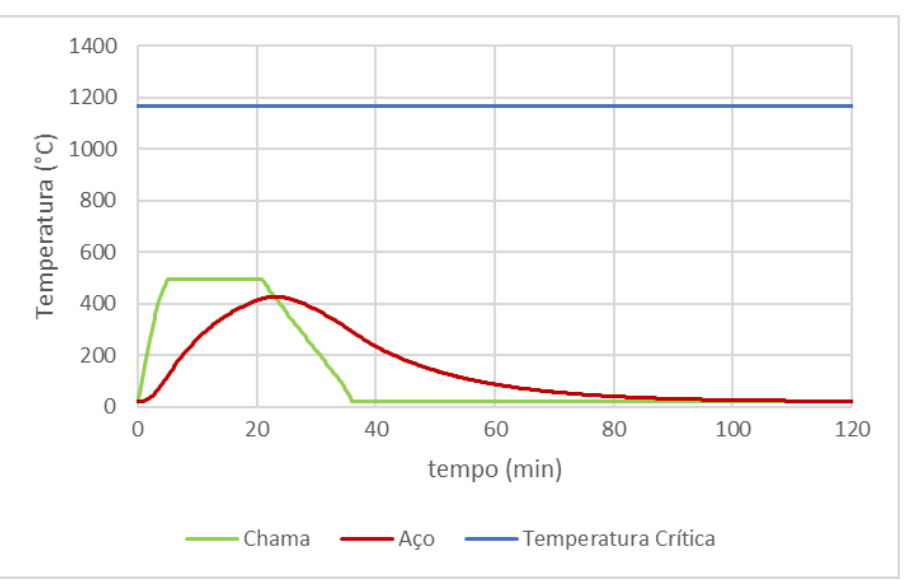

\section{Cartas de Cobertura}

Alternativamente aos métodos empregados até agora, foi realizado o dimensionamento da proteção contra incêndio através de uma carta de cobertura para argamassas projetadas (Quadro 1). Este método facilita em muito o processo de dimensionamento do revestimento de proteção contra fogo, por considerar somente o fator de massividade da seção do elemento e o 
Revista Científica do Corpo de Bombeiros Militar de Pernambuco

Artigo Publicado no Vol.05 N.13 - Edição Jul a Dez 2019 - ISSN 2359-4829

Versão on-line disponível em: $\underline{\text { http://www.revistaflammae.com }}$

tempo requerido de resistência ao fogo. A carta utilizada fixa sua temperatura crítica em $500^{\circ} \mathrm{C}$.

\section{Quadro 1 - Carta de cobertura para argamassa projetada $\left(500^{\circ} \mathrm{C}\right)$}

\begin{tabular}{|c|c|c|c|c|c|}
\hline \multirow{2}{*}{$\begin{array}{c}\text { Massividade } \\
\left(\mathbf{m}^{-1}\right)\end{array}$} & \multicolumn{5}{|c|}{ Resistência ao fogo (minutos) } \\
\cline { 2 - 6 } & $\mathbf{R} 15$ & $\mathbf{R ~ 3 0}$ & $\mathbf{R ~ 4 5}$ & $\mathbf{R ~ 6 0}$ & $\mathbf{R ~ 9 0}$ \\
\hline 100 & 10 & 10 & 12 & 15 & 21 \\
\hline 110 & 10 & 10 & 13 & 16 & 21 \\
\hline 120 & 10 & 10 & 13 & 16 & 22 \\
\hline 130 & 10 & 10 & 13 & 16 & 22 \\
\hline 140 & 10 & 11 & 13 & 16 & 22 \\
\hline 150 & 10 & 11 & 14 & 17 & 23 \\
\hline 160 & 10 & 11 & 14 & 17 & 23 \\
\hline 170 & 10 & 11 & 14 & 17 & 23 \\
\hline 180 & 10 & 11 & 14 & 17 & 23 \\
\hline
\end{tabular}

Fonte: Adaptado de Placo (2018).

Para o estudo em questão, definiu-se a massividade dos elementos, sendo estabelecida para as vigas e pilares de extremidade a exposição em 3 lados, e para os pilares centrais a exposição nos 4 lados. Dado o TRRF para o edifício em questão de 60 minutos, obteve-se as espessuras dos revestimentos (Tabela 3).

Tabela 3- Espessura dos revestimentos obtido através da carta de cobertura

\begin{tabular}{c|c|c|c}
\hline Perfil & Exposição & $\begin{array}{c}\text { Massividade } \\
\left(\mathbf{m}^{-1}\right)\end{array}$ & $\begin{array}{c}\text { Argamassa } \\
\text { Projetada }(\mathbf{m m})\end{array}$ \\
\hline W610X101 & 3 lados & 150.36 & 17 \\
\hline W610X155 & 3 lados & 107.74 & 16 \\
\hline W360X79 & 3 lados & 167.13 & 17 \\
\hline W360X79 & 4 lados & 175.28 & 17 \\
\hline
\end{tabular}

Portanto, dada a ocorrência de incêndio, considerando o dimensionamento estabelecido neste tópico, conclui-se a necessidade de revestimento contra incêndio para todos os elementos estudados, a fim de se garantir o tempo requerido de 60 minutos.

\section{Orçamento}


Revista Científica do Corpo de Bombeiros Militar de Pernambuco

Artigo Publicado no Vol.05 N.13 - Edição Jul a Dez 2019 - ISSN 2359-4829

Versão on-line disponível em: http://www.revistaflammae.com

Os custos relacionados à proteção passiva foram orçados a partir da composição de preços representada no Quadro 8. Esta composição considera a projeção pneumática de argamassa composta por uma base de gesso, vermiculita e aditivos especiais, e varia seus rendimentos de acordo com a espessura e com o elemento a ser protegido, se pilar ou viga. O custo unitário utilizado foi aquele disponível no dia da pesquisa, o qual pode variar de acordo com fabricante e local.

Quadro 2 - Composição de custo unitário de proteção passiva contra incêndio em vigas com argamassa projetada, espessura $10 \mathrm{~mm}$

\begin{tabular}{|c|c|c|c|c|}
\hline Un & Descrição & Rendimento & $\begin{array}{c}\text { Preço } \\
\text { Unitário } \\
\text { (R\$) }\end{array}$ & $\begin{array}{c}\text { Preço } \\
\text { Insumo } \\
\left(\mathbf{R} \$ / \mathbf{m}^{2}\right)\end{array}$ \\
\hline $\mathrm{kg}$ & $\begin{array}{l}\text { Argamassa Igniver "PLACO", composta por uma base de } \\
\text { gesso, vermiculita e aditivos especiais, reação ao fogo } \\
\text { classe A1, para proteção passiva contra o fogo através de } \\
\text { projeccão. }\end{array}$ & 7,000 & 2,34 & 16,38 \\
\hline $\mathrm{h}$ & $\begin{array}{l}\text { Misturadora-bombeadora para argamassas e gessos } \\
\text { projetados, de } 3 \mathrm{~m}^{3} / \mathrm{h} \text {. }\end{array}$ & 0,159 & 17,96 & 2,86 \\
\hline $\mathrm{h}$ & Aplicador de produtos isolantes. & 0,191 & 22,85 & 4,36 \\
\hline $\mathrm{h}$ & Ajudante de aplicador de produtos isolantes. & 0,191 & 17,94 & 3,43 \\
\hline$\%$ & Custos diretos complementares & 2,000 & 27,03 & 0,54 \\
\hline \multicolumn{3}{|c|}{ Custo de manutenção decenal: $\mathrm{R} \$ 6,34$ nos primeiros 10 anos. } & Total: & 27,57 \\
\hline
\end{tabular}

Fonte: CYPE, 2019

Geradas todas as composições necessárias, foram verificados os comprimentos dos perfis a serem protegidos de acordo com as metodologias estudadas, bem como definidos os perímetros dos perfis. Assim, multiplicou-se o metro linear e o perímetro dos elementos pelo valor da composição, resultando nos valores encontrados na Tabela 4.

\section{Tabela 4 - Custo de revestimento contra incêndio de acordo com metodologia empregada}

\begin{tabular}{l|c|c|c|c|c}
\hline \multirow{2}{*}{} & \multicolumn{5}{c}{ Custo (R\$) } \\
\cline { 2 - 6 } & $\begin{array}{c}\text { Cartas de } \\
\text { Cobertura }\end{array}$ & $\begin{array}{c}\text { ISO 834 - } \\
\text { Simplificado }\end{array}$ & $\begin{array}{c}\text { ISO 834 - } \\
\text { Avançado }\end{array}$ & $\begin{array}{c}\text { Curva } \\
\text { Paramétrica - } \\
\text { Simplificado }\end{array}$ & $\begin{array}{c}\text { Curva } \\
\text { Paramétrica - } \\
\text { Avançado }\end{array}$ \\
\hline \multicolumn{7}{c}{ Pórtico A } & $\mathrm{R} 391.27$ \\
\hline
\end{tabular}


Revista FLAMMAE

Revista Científica do Corpo de Bombeiros Militar de Pernambuco

Artigo Publicado no Vol.05 N.13 - Edição Jul a Dez 2019 - ISSN 2359-4829

Versão on-line disponível em: $\underline{\text { http://www.revistaflammae.com }}$

\begin{tabular}{c|c|c|c|c|c}
\hline \multicolumn{7}{c}{ Pórtico B - Compartimento A } \\
\hline Subtotal & $\mathrm{R} \$ 7,267.02$ & $\mathrm{R} \$ 4,986.54$ & $\mathrm{R} \$ 5,910.66$ & $\mathrm{R} \$ 4,986.54$ & $\mathrm{R} \$ 4,364.07$ \\
\hline Total $(2 x)$ & $\mathrm{R} \$ 14,534.04$ & $\mathrm{R} \$ 9,973.08$ & $\mathrm{R} \$ 11,821.33$ & $\mathrm{R} \$ 9,973.08$ & $\mathrm{R} \$ 8,728.15$ \\
\hline \multicolumn{7}{c}{ Pórtico B - Compartimento B } \\
\hline Subtotal & $\mathrm{R} \$ 5,847.77$ & $\mathrm{R} \$ 3,991.69$ & $\mathrm{R} \$ 4,833.66$ & $\mathrm{R} \$ 8,555.48$ & $\mathrm{R} \$ 5,558.40$ \\
\hline Total (3x) & $\mathrm{R} \$ 17,543.32$ & $\mathrm{R} \$ 11,975.06$ & $\mathrm{R} \$ 14,500.99$ & $\mathrm{R} \$ 25,666.43$ & $\mathrm{R} \$ 16,675.20$ \\
\hline \multicolumn{7}{c}{ Pórtico B - Compartimentos C e D } \\
\hline Subtotal & $\mathrm{R} \$ 7,267.02$ & $\mathrm{R} \$ 4,986.54$ & $\mathrm{R} \$ 5,910.66$ & $\mathrm{R} \$ 5,910.66$ & $\mathrm{R} \$ 6,165.82$ \\
\hline Total (4x) & $\mathrm{R} \$ 29,068.09$ & $\mathrm{R} \$ 19,946.17$ & $\mathrm{R} \$ 23,642.66$ & $\mathrm{R} \$ 23,642.66$ & $\mathrm{R} \$ 24,663.27$ \\
\hline \multicolumn{5}{c}{ Pórtico C } \\
\hline Total & $\mathrm{R} \$ 9,111.71$ & $\mathrm{R} \$ 3,866.95$ & $\mathrm{R} \$ 586.90$ & $\mathrm{R} \$ 6,135.64$ & $\mathrm{R} \$ 4,499.44$ \\
\hline TOTAL GERAL & $\mathrm{R} \$ \mathbf{6 8 , 3 4 3 . 1 5}$ & $\mathrm{R} \$ \mathbf{5 5 , 7 4 8 . 0 7}$ & $\mathrm{R} \$ \mathbf{5 9 , 5 0 8 . 6 8}$ & $\mathrm{R} \$ \mathbf{6 9 , 6 4 3 . 9 7}$ & $\mathrm{R} \$ \mathbf{5 4 , 8 6 2 . 7 0}$ \\
\hline
\end{tabular}

Os custos encontrados variaram de $R \$ 54.862,70$ para o sistema de revestimento utilizando as curvas paramétricas através do método de cálculo avançado, até $R \$ 69.643,97$ para o mesmo sistema utilizando métodos simplificados de cálculo.

A estrutura metálica dimensionada possui peso equivalente a $198.033,90 \mathrm{~kg}$. Considerando o valor do aço a $R \$ 3,85 / \mathrm{kg}$, segundo CYPE (2019), o custo estimado para a estrutura é de $R \$ 762.430,52$. Isto posto, o sistema de revestimento contra incêndio dimensionado através de cartas de cobertura equivale a $8,96 \%$ do custo da estrutura. Segundo o modelo que considera a curva ISO 834 , o custo equivale a $7,31 \%$ para o modelo simplificado e $7,81 \%$ para o modelo avançado. Os modelos embasados nas curvas paramétricas variaram de $9,13 \%$ a $7,20 \%$ para os métodos simplificado e avançado, respectivamente.

\section{CONSIDERAÇÕES FINAIS}

De forma a garantir a segurança das edificações em situação de incêndio, suas estruturas devem ser capazes de assegurar a estabilidade por um tempo mínimo, a fim de que seja possível a evacuação total de seus usuários. O presente estudo buscou analisar e comparar maneiras de se dimensionar estruturas de aço de modo a alcançar tal objetivo. 
As análises de tempo de resistência ao fogo utilizando a curva de incêndio padrão ISO 834 alcançaram resultados diversos de acordo com a metodologia empregada. Para uma abordagem simplificada através da análise por elementos houve maior necessidade de proteção nos pórticos das extremidades do edifício, se comparado ao mesmo modelo utilizando metodologia avançada. Entretanto, o modelo avançado considerou maior necessidade de proteção para os pórticos intermediários, dada a consideração da reordenação dos esforços pela aplicação das cargas de incêndio na estrutura, visto que esta curva apresenta característica sempre ascendente. Em detrimento disto, o modelo avançado utilizando a curva ISO 834 se mostrou mais oneroso do que o simplificado utilizando a mesma curva.

Comparando-se estes resultados com aqueles obtidos através das curvas paramétricas, há uma inversão nos resultados observados. Em detrimento das características dos compartimentos e da carga de incêndio, o modelo considera a ocorrência de um flashover súbito na edificação, o qual eleva a temperatura de quase todos os elementos analisados acima de suas temperaturas críticas. Assim, o modelo simplificado acaba por considerar a necessidade de proteção em todos estes, encarecendo o modelo e o tornando o mais oneroso dentre todos. Todavia, em diversos casos, a temperatura máxima destes perfis passa em pouco a crítica, seguida de um rápido resfriamento através da consideração dos diversos elementos ativos de proteção contra incêndio. Através do emprego do MEF utilizando a metodologia avançada, o rearranjo dos esforços e a redistribuição de temperatura acabou por reduzir a necessidade de proteção em alguns elementos, tornando este 0 modelo mais econômico dentre os estudados.

Os dimensionamentos de revestimento contra incêndio embasados nas cartas de cobertura apresentaram o segundo maior custo de proteção, distante apenas $1,9 \%$ do mais oneroso aqui estudado. Neste caso, todos os elementos observados apresentaram necessidade de revestimento, o que se justifica pela aplicação de um único parâmetro para definição da proteção. Em vista disso, a 
Revista Científica do Corpo de Bombeiros Militar de Pernambuco

Artigo Publicado no Vol.05 N.13 - Edição Jul a Dez 2019 - ISSN 2359-4829

Versão on-line disponível em: http://www.revistaflammae.com

aplicação deste métodotende a incorrer em custos desnecessários em grande parte dos casos.

Conclui-se por fim, através deste estudo, o impacto que as análises embasadas em curvas paramétricas têm no custo e na própria segurança da edificação, visto que este é o modelo que mais se aproxima das condições reais das edificações. Os modelos de análises por elementos podem ou não serem mais conservadores, dependendo completamente das características do ambiente analisado, com uma provável minimização de custos através do emprego de métodos avançados que consideram o rearranjo dos esforços, como observado através desta pesquisa.

\section{REFERÊNCIAS BIBLIOGRÁFICAS}

ASSOCIAÇÃO BRASILEIRA DE NORMAS TÉCNICAS. NBR 14432:Exigências de resistência ao fogo de elementos construtivos de edificações - Procedimento. Rio de Janeiro, 2000.

. NBR 5628: Componentes construtivos estruturais Determinação da resistência ao fogo. Rio de Janeiro, 2001.

NBR 14323: Projeto de estruturas de aço e de estruturas mistas de aço e concreto de edifícios em situação de incêndio. Rio de Janeiro, 2013.

BELLEI, I. H.; PINHO, F. O.; PINHO, M. O. Edifícios de múltiplos andares em aço. 2. ed. São Paulo: PINI, 2008.

CAMPOS, A. T. Enquadramento da legislação de segurança contra incêndios em edifícios existentes no Porto: estudo de caso: propostas alternativas para adaptação às exigências regulamentares. Dissertação (Mestrado em Engenharia Civil). Universidade de Porto. Portugal. 2012.

CARVALHO, P. A. de O. Análise comparativa de estrutura metálica em situação de incêndio: curva ISO 834 x curvas paramétricas. Palmas, 2018.

CEN, European Committee for Standardisation. EN 1991-1-2:2010, Eurocode 1, Actions on structures - Part 1-2: General actions - Actions on structures exposed to fire". ICS: 13.220.50; 91.010.30; 91.808.40. 2010a. 
EN 1993-1-2:2010, Eurocode 3, Design of Steel Structures - Part 1-

2: General rules - Structural fire design". ICS: 13.220.50; 91.010.30; 91.080.10. 2010b.

COSTA, C. N.; SILVA, V. P. Revisão histórica das curvas padronizadas de incêndio. In: SEMINÁRIO INTERNACIONAL NUTAU, 2006, São Paulo.

Faculdade de Arquitetura e Urbanismo da Universidade de São Paulo. Anais... São Paulo, 2006.

COUTO, C. Resistência mecânica em situação de incêndio. Estabilidade de pórticos metálicos em situação de incêndio. Dissertação (Mestrado em Construção Metálica eMista) - Universidade de Coimbra, Coimbra. 2011.

CYPE. Gerador de Preços. Disponível em:

<http://www.brasil.geradordeprecos.info/>. Acessoem: 02 mar. 2019.

FRANSSEN, J.-M. SAFIR, A Thermal/Structural Program Modelling

Structures under Fire. Engineering Journal, A.I.S.C., vol. 42, 2005. p. 143158.

INTERNATIONAL ORGANIZATION FOR STANDARDIZATION (ISO). FireResistance Tests - Elements of Building Construction - Part 1.1: General Requirements for Fire Resistance Testing. ISO 834. Geneva: ISO/TC, 1990.

LOPES, N. et al. Modelação numérica do comportamento ao fogo de uma estrutura em aço inoxidável em situação de incêndio. In: actas do $V$ Congresso de Construção Metálica e Mista. 2005.

MARTINS, M. M. Dimensionamento de estruturas de aço em situação de incêndio. Dissertação (Mestrado em Engenharia de Estruturas). Universidade Federal de Minas Gerais. 2000

MESQUITA, A. Verificação da resistência de estruturas de aço ao fogo. Dissertação (Mestrado em Engenharia Civil). Universidade de Lisboa. Portugal. 2013.

PANNONI, F. D. Princípios da Proteção de Estruturas Metálicas em Situação de Corrosão e Incêndio. GERDAU. 6aㅡ. ed. 2015. Disponível em: <http://www.skylightestruturas.com.br/downloads/manual-protecao-deestruturas.pdf>. Acesso em: 20/07/2018.

PLACO. Guia Placo: soluções inovadoras em gesso. Portugal, 2018.

Disponível em: <https://www.placo.pt/guia-placor>. Acesso em: 04/03/2019. 
REIS, A. S. Determinação de cenários de incêndio em edifícios.

Dissertação (Mestrado em Engenharia Civil). Universidade de Aveiro. Portugal. 2011.

SILVA, V. P. Estruturas de aço em situação de incêndio. São Paulo: Zigurate Editora, 2001.

SILVA, V. P. Estruturas em situação de incêndio; diferenças entre normas brasileira e europeia. Escola Politécnica da Universidade de São Paulo. 2015.

SILVA, T. D. de A. e. Buckling lengths of columns in unbraced steel frames exposed to fire. Tese (DoutoradoemEngenharia Civil). Universidade de Aveiro. Portugal. 2016.

VILA REAL, P. Incêndio em estruturas metálicas - cálculo estrutural. 4. ed. Lisboa: Editora Orion, 2003.

VILA REAL, P.; FRANSSEN, J. M. Elefir-EN V1.4.5: Software for Fire Design of Steel Structural Members According the Eurocode 3. Disponível em <http://elefiren.web.ua.pt/>. 2011 